\title{
Trends in wheat germ cell free protein expression system with an emphasis on up-scaling and industrial application
}

\author{
Bhanu Revathi K ${ }^{1}$, Kolluru V. A. Ramaiah ${ }^{2}$, Alan G. Hinnebusch ${ }^{3}$, Abani K. Bhuyan ${ }^{4}$, Sivasai KSR ${ }^{1}$, Akulapalli \\ Sudhakar ${ }^{5,6,7}$ and Laxminarayana Burela ${ }^{1, *}$ \\ 1. Dept. of Biotechnology, Sreenidhi Instt. of Science and Technol., Yamnampet, Ghatkesar, Hyderabad, India. \\ 2. Dept. of Biochemistry, School of Life Sciences, University of Hyderabad, Hyderabad, India \\ 3. Laboratory of Gene Regulation and Development, National Instt. of Child Health and Human Development, \\ National Instt. of Health, Bethesda, MD 20892, USA. \\ 4. School of Chemistry, University of Hyderabad, Hyderabad, India. \\ 5. Cell Signaling and Tumor Angiogenesis Lab, Dept. of Genetics, Boys Town National Research Hospital, Omaha, \\ NE, USA. \\ 6. Dept. of Biomedical Sciences, Creighton University School of Medicine, Omaha, NE, USA \\ 7. Dept. of Biochemistry and Molecular Biology, University of Nebraska Medical Center, Omha, NE, USA \\ burelal12@gmail.com*
}

\begin{abstract}
Cell-free translation systems have developed significantly over the last 2 decades and improvements in yield have resulted in their use for in vitro protein production in the laboratory. Such cell free systems enable the expression of cytotoxic, regulatory or unstable proteins that cannot be expressed in living cells. We compare the uses of different cell-free translation systems and review recent findings that support the possibility of scaling up and thereby enhancing the industrial application of wheat germ cell free protein expression.
\end{abstract}

Keywords: Cell free biology, in vitro protein expression, scale up of translation, wheat germ extract

Introduction

Cell free protein expression is a rapid and high throughput technology to express proteins from their genes. Cell free protein synthesis uses a cell free lysate from $E$. coli cells, rabbit reticulocytes or wheat germ to supply protein translation machinery. In vitro translation in general, can be accomplished using a crude lysate from any given organism (that provides the translational machinery, accessory enzymes, tRNA and factors) along with exogenously added mRNA template, amino acids and an energy supply (Ramaiah \& Davies, 1985; Janaki et al., 1995). This kind of in vitro translation is called 'uncoupled' as opposed to the 'coupled' or 'combined' transcription and translation in which the mRNA is transcribed in situ from a DNA template added to the reaction. Many eukaryotic proteins that fold correctly in eukaryotes, misfold in E. coli due to lack of co-operativity of a large number of eukaryotic chaperones and their intimate association with translation and eukaryotic ribosomes (Hillebrecht \& Chong, 2008).

Cell free systems were used extensively for studies on translation control in addition to protein production (Laxminarayana et al., 2002, Szamecz et al., 2008). Further, in vitro synthesis of proteins in cell free extract has a variety of applications such as rapid identification of gene products (e.g., proteomics), localization of mutations through synthesis of truncated gene products, protein folding studies and incorporation of modified or unnatural amino acids for functional studies. An overview of in vitro translation in wheat germ lysates is described in Fig. 1. In vitro translation systems have various advantages over in vivo gene expression when the overexpressed product is toxic to the host cell, when the product is insoluble or forms inclusion bodies or when the protein undergoes rapid proteolytic degradation by intracellular proteases. Bacterial extracts are often unsuitable for translation of RNA because exogenous RNA is rapidly degraded by endogenous nucleases whereas wheat germ cell free translation offers a high throughput system for cell free translation of eukaryotic proteins because of absence of inhibitors. Wheat germ lysates are being preferred because of their ease of availability and application. Vast amount of work is being done in efficient design of translation systems from batch mode to continuous mode. With these developments, high throughput yield was obtained for long periods of time and with low extract volumes. The use of continuous mode design for preparative scale of protein synthesis in wheat germ lysates indicates that reactors can be designed for production in industrial scale as available for E. coli extracts. Proteins of high commercial value such as peptide hormones, interferons, diagnostic enzymes and vaccines may possibly manufactured using such systems with high level of purity and lesser number of process steps.
Review

CIndian Society for Education and Environment (iSee)
"Wheat germ cell free protein expression system" http://www.indjst.org
Bhanu Revathi et al. Indian J.Sci.Technol. 
Advantages of cell free protein expression as compared to chemical synthesis and in vivo expression

Among the 3 strategies for protein synthesis, chemical synthesis is not applicable for the synthesis of long peptides; in vivo expression systems produce only those proteins that do not affect host cell physiology. However, cell free protein expression system can synthesize large proteins without interfering with host cell physiology with similar speed and accuracy as that of the in vivo expression. Other advantages are the direct expression of PCR products, incorporation of unnatural amino acids and site-directed isotope labeling. In most cases, the further applications of the synthesized protein depend on its purity. Cell-free protein expression systems do not contain the proteins or other contaminants that are otherwise present in in vivo systems rendering purification easy. Because of the lack of any intervention from translation from the host cell, proteins can be produced even in $\mathrm{mg}$ levels per $\mathrm{ml}$ of reaction mix (Hillebrecht \& Chong, 2008). Further cell free protein expression systems are suitable for high-throughput strategies because of reduced reaction volumes and process time. Another added advantage of the cell free protein expression system is that it can be used for in vitro evolution of proteins with selected biological properties and it is possible to create proteins with new or even improved biological activities by introducing naturally modified amino acids into specific positions of a protein (Lamla et al., 2002).

\section{Introduction of wheat germ and its translation system}

Wheat germ is a by-product in wheat mills. In the perspective of cell free biology, wheat germ has embryos that contain all the necessary macromolecular components required for the translation of mRNA in to protein. However, wheat germ extract by itself consists of relatively low levels of its own mRNA. Wheat germ extract is a convenient alternative to the rabbit reticulocyte lysate. Wheat germ extract efficiently translates exogenous RNA from a variety of organisms from viruses and yeast to higher plants and mammals. Wheat germ extract is recommended for translation of RNA containing small fragments of double-stranded RNA or oxidized thiols which are inhibitory to the rabbit reticulocyte lysate.

\section{Significance of wheat germ} lysates for cell free protein expression system

Although the E. coli coupled systems express higher proteins and ease of operation, these systems are not feasible for highly folded eukaryotic proteins. Eukaryotic-based systems provide

Review

CIndian Society for Education and Environment (iSee)
Table 1. Advantages of wheat germ lysate as compared to rabbit reticulocyte lysates (Babu \& Ramaiah, 1996; Madin et al., 2000; Spirin, 2004)

\begin{tabular}{|l|c|}
\hline $\begin{array}{l}\text { Wheat germ lysate } \\
\text { and low cost }\end{array}$ & $\begin{array}{c}\text { Rabbit reticulocyte lysate } \\
\text { ethical issues }\end{array}$ \\
\hline Easy to make & Difficult to make \\
\hline $\begin{array}{l}\text { No endogenous } \\
\text { mRN A }\end{array}$ & $\begin{array}{c}\text { Possess globin RNA and } \\
\text { needs nuclease treatment }\end{array}$ \\
\hline $\begin{array}{l}\text { Very low levels of } \\
\text { endogenous } \\
\text { amino acid pool }\end{array}$ & Low background levels \\
\hline Easy scale-up & $\begin{array}{c}\text { Preparative amounts of } \\
\text { protein not yet developed, } \\
\text { because it is not available } \\
\text { in large quantities }\end{array}$ \\
\hline
\end{tabular}

"Wheat germ cell free protein expression system" http://www.indjst.org
Fig. 1. Cell free protein expression using wheat germ lysate

In vitro translation

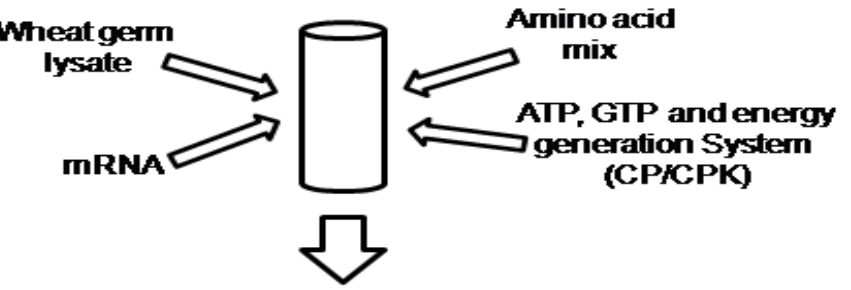

Electrophoresis

Detection of protein

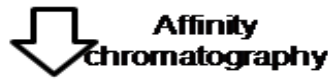

Purified orotein

a better platform for post-translationally modified proteins. E. coli extracts are inefficient in terms of coupled transcription and translation of PCR generated DNA fragments due to the contamination by the mRNA and DNA degradation enzymes originating from the cells that decrease the stability of the templates and reduces yields. In contrast, mRNAs of wheat germ lysates are stable for long periods of time (Sawasaki et al., 2002). Further, combined eukaryotic cell-free systems have been developed that combine a prokaryotic phage RNA polymerase/promoter with eukaryotic extracts and utilize an exogenous DNA template for in vitro protein synthesis (eg. combined reticulocyte lysate \& wheat germ extract). Cell free protein synthesis is also carried out in lysates obtained from Saccharomyces cerevisieae, Drosophila and other sources but wheat germ lysates are easy to operate and can be prepared readily. Mammalian cell expression systems can be effective tool but are plagued by difficulties in purifying recombinant proteins, limitations on the size of the recombinant protein expressed, expression time and unstable protein expression (Roberts \& Patterson, 1973). Rabbit reticulocyte lysate cell-free expression system has not been adapted to provide preparative amounts of synthesized proteins because of setbacks enumerated in Table 1. Many of these problems can be circumvented by using wheat germ cell-free translation system. As the system is derived from eukaryotic plant source, it can be more convenient and promising cell-free translation system to synthesize eukaryotic multidomain proteins in folded state on a preparative scale (Madin et al., 2000). Further, reported protein yields for the rabbit reticulocyte lysate are in the $\mathrm{mg}$ or in the fraction of $\mathrm{mg} / \mathrm{ml}$ of reaction range whereas protein yields of the wheat germ extract are typically 2

Bhanu Revathi et al. Indian J.Sci.Technol. 
orders of magnitude higher (Katzen et al., 2005). In wheat germ lysates many advantages have come up while the limitations were being overcome suggesting the feasibility for pharmaceutical protein production, producing patientspecific vaccines and evolving new enzymes. Unpublished data from our group indicate the preparation of wheat germ lysates that were active for in vitro translation of Brome Mosaic Virus (BMV) RNA. The efficiency of protein synthesis in these lysates is more as compared to commercially available lysates. Advantages of wheat germ lysates in comparison with rabbit reticulocyte lysates for cell free protein expression is given in Table 1.

\section{Optimization of the 5' and 3' UTRs in mRNA}

Optimization for structure and concentration of mRNA was done for increasing the yield of protein in wheat germ extracts. The capped mRNA showed a narrow optimum whereas the $\Omega$ with the GAA trinucleotide at the 5 '-end $($ GAA $\Omega$ ) containing mRNAs with a longer 3'-UTR can be used in relatively large amounts over a broad range of concentrations. An efficient expression vector, pEU (plasmid of Ehime University, Matsuyama, Japan) was constructed to produce large proteins and operate for longer periods of time using the robustness of translation shown by wheat germ lysates. A split primer PCR set was designed to skip the labor of various molecular biology steps to generate a template for translation. The given UTR elements can be introduced into the upstream primers (containing SP6 promoter \& GAA $\Omega$ ) for cDNA amplification. The PCR product can be directly used for the in vitro transcription reaction without purification. The resultant translation system produced proteins for a long period of 14 days with supplementation of mRNA required only for every 2 days (Sawasaki et al., 2002).

\section{Stability of $m R N A$ s added to lysates}

The stabilities of different mRNA species were analyzed in a reticulocyte lysate under protein synthesizing conditions. In all cases examined the relative mRNA degradation by reticulocyte ribonucleases correlated with the extent of $(U)$ nA sequences with in the 3 ' non-coding region. In case of wheat germ extract, it has low background incorporation due to its low levels of endogenous mRNA. When using RNA synthesized in vitro, the presence of a 5' cap structure may enhance translational activity in wheat germ extracts. Further, the synthesis of poly $(A)$ examined in wheat germ extracts under conditions used for protein synthesis. The wheat germ extract contained both poly (A)-polymerizing and poly (A)-hydrolytic activities. It is also observed that, addition of human placental RNase inhibitor at $10 \mu \mathrm{g} / \mathrm{ml}$ to wheat germ extract, prior to the addition of mRNA, resulted in significant increase in the yield of proteins synthesized.
Vol. 3 No. 3 (Mar 2010)

ISSN: 0974- 6846

\section{Purification of the synthesized protein}

Madin et al. (2000) produced Di Hydro Folate Reductase (DHFR), Green Florescent Protein (GFP) and luciferase proteins from wheat germ lysates to analyze the development of a robust cell free translation system. The proteins produced were detected by running aliquots withdrawn and separated on SDS PAGE. DHFR was purified by passing through a methotrexate-agarose column and its activity was defined colorimetrically. In continuous modes of cell free protein expression systems the ultra filtration membrane separates the translation machinery from the purified protein and hence, recovery is made easier as the case of SFCF (Semi-continuous flow cell free translation) and CFCF (Continuous flow cellfree translation) systems. Malarial proteins expressed in wheat germ cell free lysates were produced in bilayer translation reaction mode. After translation, they were centrifuged and the supernatant was passed through Amicon Ultra centrifugal filter units (10 KDa molecular mass cut off) (Tsuboi et al., 2008).

\section{Affinity tagging for recovery of synthesized products}

In general short peptide tags near the terminals of the protein sequence do not influence the biological activity of the protein. These tags when attached to the protein sequence help in the retention of these proteins while passing through a chromatography column. The chromatography must be performed under physiological conditions, so that the fusion protein can be obtained in native state. One of the short affinity tags used is the 9 amino acid peptide with intrinsic streptavidin binding activity (Strep-tag I). An eight amino acid peptide sequence variant shows affinity towards Streptavidin and StrepTactin (Strep-tag II). Genes for Strep tag-I and Strep tag-Il were fused to the C-terminus of bovine heart FABP (fatty acid binding protein) and CAT (Chloramphenicol Acetyl Transferase) and were cloned into plasmids. The recombinant proteins produced were subjected to purification using StrepTactin-Sepharose affinity column. Ribosomal display was used to purify the fusion proteins tagged with poly-His (His tag of 6 consecutive His residues). In ribosomal display, a 3'stem loop mRNA structure encoded into the DNA sequence is introduced from the untranslated region of T7 sequence. The resulting protein can be selectively bound to $\mathrm{Ni}$ (II)-IDAAgarose column. This method was adopted for purifying FABP (Lamla et al., 2002). Some proteins were purified using Ni-nitrilo-acetic acid agarose column or through Glutathione- Sepharose 4 B column (the GST tag was removed by cleavage with tobacco etch virus protease). The most convenient mode of separation of polypeptide product is possible in continuous exchange cell-free (CECF) translation system wherein the produced polypeptide is separated from the relatively low molecular weight products (Spirin, 2004).
Review

CIndian Society for Education and Environment (iSee)
"Wheat germ cell free protein expression system" http://www.indjst.org
Bhanu Revathi et al. Indian J.Sci.Technol. 


\section{Scale up of cell free translation systems}

Scale up of cell free translation was demonstrated by conducting the reaction in several modes. Initial developments were done using a batch system and further extended SFCF systems where in the substrates are provided intermittently and 2 other modes that have been successful in reducing the operation costs are the CFCF and CECF translation systems. In a CFCF translation system, the translation mixture is confined in a flow-through cell by an ultra filtration membrane to remove the products as well as feed the system i.e., the components of the protein synthesizing machinery are enclosed in a liquid-phase reactor. The CECF represents a simplified version of the previous one, wherein the translation system is enclosed in a simple dialysis bag for replenishing substrates and removing low molecular weight products by diffusion exchange across the membrane during the reaction (Spirin, 2004). A comparison of utility of CECF and CFCF systems is indicated in Table 2. Wheat germ lysates are used to produce a wide variety of industrially applicable proteins. For commercialization, these proteins need to be scaled up for higher yields. A careful analysis of the procedure of extract preparation and duration of the process must be done to reduce the operating costs. In E. coli lysates, cellfree reaction works well when the reaction mixture is allowed to spread as a "big drop" in a thin film format on hydrophobic surfaces, giving high yields. For granulocyte macrophage colony stimulating factor- single chain fragment variable (GMCSF-SCFV) fusion protein vaccine candidates, using $E$. coli lysates, the scale up was done initially in test tubes, extended to thin film reactions and to bubble column reactor operations. An antifoaming agent was added to the bubble column reactor to avoid foaming in high volumes. This addition did not affect the protein produced in any way. In test tube reactions, scale up was found to reduce the volumetric yield, however, in case of thin film and bubble column reaction modes, the yields of total and soluble product were preserved after scale up. Further, in vitro translation needs replenishment of energy to convert GDP to GTP. Translation requires high expenditure of energy and hence the amount of energy currency used is of utmost importance in case of scale up of the process. These principles were then extended to stirrer tank reactor formats mostly notable for the production of human insulin-like growth factor-I (IGF-I). IGF-I solubility and activity requires the formation of disulfide bonds even though it is a rather small protein (7,649 Da). Controlling the redox-SH/S-S conditions and increasing the solubility of the protein result in higher yield of an active protein (Swartz, 2006). The main limitation faced by batch reactors is their short life time and low yields due to rapid depletion of energy source. In cell free translation systems that operate in continuous flow mode, the reaction can be extended up to 20 hours, hence increasing the product yield by several folds. In Semi-Continuous or Continuous Exchange Cell-Free modes, applicability is limited for high throughput processes which require miniaturization and automation. A bilayer system is also followed for diffusion systems devoid of membranes and is compatible with high throughput formats. The use of chaperones and post translational modification proteins is exogenous and entirely protein dependant (Katzen et al., 2005). Addition of glutathione redox buffer and disulfide isomerase and removal of dithiothreitol enhances disulfide bond formation. A typical "protein bioreactor" was designed (Lamla et al., 2002) wherein, the CFCF system uses an ultra filtration membrane to remove AMP, GDP, $\mathrm{Pi}$, amino acids, etc., and retains the polypeptide on its surface. A pump each is used for feeding the reactor with amino acids and energy components and for pumping the polypeptide to an affinity column for purification. CFCF systems for wheat germ lysates indicate the possibility for applications to large scale protein production. The preparative scales of proteins such as luciferase, GFP, TMV (Tobacco Mosaic Virus) $126 \mathrm{KDa}$ replicase (a major product during infection) were produced in high quantities, consuming less time in wheat germ lysates (Madin et al., 2000). Roche Diagnostics GmbH has launched Continuous Exchange Cell Free lysates of $E$. coli extracts in RTS 500 and RTS 9000 reactors. These reactors have already produced high yields, opening up possibilities for automation and computerization of in vitro protein synthesis in other extracts (Spirin, 2004). In general, yield per $\mathrm{ml}$ of incubation mixture can vary from $50 \mu \mathrm{g}$ to $4 \mathrm{mg}$ of protein depending on its size, its solubility, the expressivity of the template and the type and quality of the cell extract used.

\section{Improving yield}

In general CFCF systems are inferior when compared to batch reactors. By comparing the synthesized protein present between, in the reaction chamber and in the fedout solution in the CFCF-system, it appeared that much of the synthesized protein remained in the reaction chamber. Addition of a nonionic detergent, $n$-dodecyl $\beta$ $D$-maltoside, to the feeding solution resulted in enhancement of the productivity in the CFCF-system indicating that the permeability of the membrane to the protein might be one of the most influential factors affecting the productivity of the CFCF-system (Nishimura et al., 1995). The continuous mode reaction can be optimized to give proteins at high yields by modifying the reaction chamber, reaction conditions, flow of substrates and clarifying the instability of extracts.

\section{Applications of wheat germ cell-free translation system}

Developing cell-free lysates to increase robustness and yields paves way for a series of applications delineating the scope of modern proteomics, including the following: high-throughput enzymatic testing of a large number of genomic expression products, high-throughput crystallization of proteins and identification of their three-
Review

CIndian Society for Education and Environment (iSee)
"Wheat germ cell free protein expression system" http://www.indjst.org
Bhanu Revathi et al. Indian J.Sci.Technol. 
dimensional structure, rapid evolutionary design of proteins, construction of protein-protein interaction systems, and industrial-scale protein production. Initially several proteins were synthesized in wheat germ extracts in preparative scale to address the possibility of large scale production. Continuous exchange system using dialysis was used for successful production of proteins from reporter genes and also viral coat proteins (Sawasaki et al., 2002). To develop and incorporate the necessary technologies and methods into a highthroughput production environment, a phased process can be followed as described here. The process includes research, design, and development; modular and pilotscale deployment; and final integration and scale up into operational procedures. Wheat germ cell free translation was used for production of many proteins including recombinant as well as several therapeutic proteins as shown below:

1. A novel wheat germ cell-free technology was developed for production and purification of proteins from Arabidopsis thaliana, human, mouse, rat and zebra fish. The expression and purification protocols for both small-scale testing (microgram) and largescale production (milligram) of $\mathrm{N}$-(His) $6^{-}$and N-GSTtagged proteins were described. This produces both unlabeled and labeled proteins required for structurebased determinations by NMR spectroscopy or X-ray crystallography (Viranov et al., 2008).

2. Wheat germ lysates were found to be effective tools for in vitro proteome research to create a "human proteome factory". 13364 human proteins were tested for expression in these lysates and most of them were found to show biological activity. Many cytokines containing disulfide bonds were also expressed in native form in a nonreducing wheat germ lysate (Goshima et al., 2008).

3. In vitro translation of human stearoyl-CoA desaturase carried out using wheat germ lysate in the presence of unilamelar liposomes, and nearly complete transfer of the expressed integral membrane protein into the liposome was observed. This integral membrane protein was also found to be catalytically active when co-translated and expressed with cytochrome $b_{5}$. This demonstrated the applicability to the purification and integration of membrane proteins (Goren \& Fox, 2008).

4. A continuous flow cell-free translation system was used for the production of preparative amounts of interleukin-6 (IL-6) from a template that produced uncapped mRNA using an SP6 polymerase for about 50 hours and producing $1.25 \times 10^{6}$ units with $>80 \%$ purity. This work highlights the feasibility for enhanced in vitro translation for rapid expression of cloned templates (Volyanik et al., 1993).

5. An unnatural amino acid 3-lodo-L-tyrosine was incorporated in the place of tyrosine (site-specific incorporation) in the mammalian Ras protein by means of a genetically engineered modified tRNA- synthetase in a wheat germ cell-free lysate mediated translation (Kiga et al.,2002).

6. Other commercially important proteins such as preproinsulin, HIV coat proteins, malarial proteins Pfs25, PfCSP and PfAMA1 (Tsuboi et al., 2008) for developing novel vaccines were expressed efficiently in wheat germ cell-free systems.

\section{Conclusion}

Cell free translation systems including wheat germ lysates are extensively used to discover the molecular mechanisms of protein biosynthesis and in basic sciences. Now these cell free systems are employed for technological applications of in vitro protein production. For expression of exogenous proteins in wheat germ lysates, the robustness of the system and its ability to produce a wide range of proteins in functionally active form is promising. Further, these proteins produced in preparative amounts can be scaled up to industrial level using continuous (CECF and CFCF) systems.

Table 2. Comparison of Continuous Exchange Cell free (CECF) and Continuous Flow Cell free (CFCF) systems for cell free protein expression (Spirin, 2004; Katzen et al., 2005)

\begin{tabular}{|l|l|}
\hline CECF & \multicolumn{1}{|c|}{ CFCF } \\
\hline $\begin{array}{l}\text { Simple mode of } \\
\text { operation involving a } \\
\text { dialysis bag, easy to } \\
\text { construct and low cost }\end{array}$ & $\begin{array}{l}\text { Complex construction with feed } \\
\text { and outlet pumps, sophisticated } \\
\text { and high cost of reactor }\end{array}$ \\
\hline $\begin{array}{l}\text { Passive exchange of low } \\
\text { molecular weight } \\
\text { substrates }\end{array}$ & $\begin{array}{l}\text { Active exchange of low } \\
\text { molecular weight substances } \\
\text { and by-products }\end{array}$ \\
\hline $\begin{array}{l}\text { Recovery of purified } \\
\text { protein by containment } \\
\text { in dialysis bag along with } \\
\text { translational machinery }\end{array}$ & $\begin{array}{l}\text { Recovery by an Ultra-filtration } \\
\text { membrane that retains } \\
\text { translational machinery and } \\
\text { protein is flown out. }\end{array}$ \\
\hline $\begin{array}{l}\text { Lifetime depends on } \\
\text { dialysis bag; productivity } \\
\text { depends on nature of the } \\
\text { protein synthesized }\end{array}$ & $\begin{array}{l}\text { Longer lifetime and higher } \\
\text { productivity can be achieved. }\end{array}$ \\
\hline $\begin{array}{l}\text { Automation and } \\
\text { monitoring is difficult to } \\
\text { accomplish }\end{array}$ & $\begin{array}{l}\text { Control of reaction, reaction } \\
\text { mixture and also protein folding } \\
\text { can be monitored. Programming } \\
\text { of flow and automation possible. }\end{array}$ \\
\hline $\begin{array}{l}\text { Product may be soluble } \\
\text { or insoluble and high } \\
\text { molecular weight protein } \\
\text { products can be easily } \\
\text { separated }\end{array}$ & $\begin{array}{l}\text { Protein product must be soluble } \\
\text { and not applicable to high } \\
\text { molecular weight protein } \\
\text { products. }\end{array}$ \\
\hline
\end{tabular}

\section{Acknowledgements}

Special thanks to the Management, Director and Principal of Sreenidhi Institute of Science and Technology for their support.

\section{References}

1. Babu SV and Ramaiah KV (1996) Type 1 phosphatase inhibitors reduce the restoration of guanine nucleotide exchange activity of eukaryotic
Review

CIndian Society for Education and Environment (iSee)
"Wheat germ cell free protein expression system" http://www.indjst.org
Bhanu Revathi et al. Indian J.Sci.Technol. 
initiation factor 2B inhibited reticulocyte lysates rescued by hemin. Arch. Biochem. Biophys. 327(2), 201-218.

2. Goren M A and Fox BG (2008) Wheat germ cell-free translation, purification and assembly of a functional human stearoyl-CoA desaturase complex. Protein Expression Purification. 62 (2), 171-178.

3. Goshima N, Kawamura Y, Fukumoto A, Miura A, Honma R and Satoh R (2008) Human protein factory for converting the transcriptome into an in vitroexpressed proteome. Nat. Methods. 5(12), 10111017.

4. Hillebrecht JR and Chong S (2008) A comparative study of protein synthesis in in vitro systems: from the prokaryotic reconstituted to the eukaryotic extractbased. BMC Biotechnology 8:58

5. Janaki N, Krishna VM and Ramaiah KV (1995) Phosphorylation of wheat germ initiation factor 2 (elF2) by N-ethylmaleimide-treated wheat germ lysates and by purified casein kinase II does not affect the guanine nucleotide exchange on elF-2. Arch. Biochem. Biophys. 324 (1), 1-8.

6. Katzen F, Chang G and Kudlicki W (2005) The past, present and future of cell-free protein synthesis. Trends Biotechnol. 23(3), 150-156.

7. Kiga D, Sakamoto K, Kodama K, Kigawa $\mathrm{T}$ and Matsuda T (2002) An engineered Escherichia coli tyrosyl-tRNA synthetase for site-specific incorporation of an unnatural amino acid into proteins in eukaryotic translation and its application in a wheat germ cellfree system. Proc. Natl. Acad. Sci. 99(15), 97159720.

8. Lamla T, Stiege W and Erdmann VA (2002) An improved protein bioreactor. Mol. Cellular Proteomics 1.6, 466- 471.

9. Laxminarayana B, Krishna VM, Janaki $N$ and Ramaiah K V (2002) Translation and phosphorylation of wheat germ lysate: phosphorylation of wheat germ initiation factor 2 by casein kinase $\mathrm{II}$ and in $\mathrm{N}$ ethylmaleimide-treated lysates. Arch. Biochem. Biophys. 400(1), 85-96.

10. Madin K, Sawasaki T, Ogasawara $T$ and Endo $Y$ (2000) A highly efficient and robust cell-free protein synthesis system prepared from wheat embryos: plants apparently contain a suicide system directed at ribosomes. Proc. Natl. Acad. Sci. 97, 559-564.

11. Nishimura N, Kitaoka $Y$ and Niwano M (1995) Enhancement of protein synthesis in continuous-flow, cell-free system by improvement of membrane permeation. J. Fermentation Bioengg. 80(4), 403405.

12. Ramaiah KVA and Davies E (1985) Wounding of aged pea epicotyls enhances the reinitiating ability of isolated ribosomes. Plant Cell Physiol. 26 (7), 12231231.

13. Roberts BE and Patterson BM (1973) Efficient translation of tobacco mosaic virus RNA and rabbit
Vol. 3 No. 3 (Mar 2010)

ISSN: 0974- 6846

globin 9S RNA in a cell-free system from commercial wheat germ. Proc. Natl. Acad. Sci. 70, 2330-2234.

14. Sawasaki, T Ogasawara, R Morishita and $Y$ Endo (2002) A cell-free protein synthesis system for highthroughput proteomics. Proc. Natl. Acad. Sci. 99, 14652-14657.

15. Spirin AS (2004) High-throughput cell-free systems for synthesis of functionally active proteins. TRENDS in Biotechnol. 22(10), 538-545.

16. Swartz J (2006) Developing cell-free biology for industrial applications. J. Ind. Microbiol. Biotechnol. 33(7), 476-485.

17. Szamecz B, Rutkai E, Cuchalová L, Munzarová V, Herrmannová A, Nielsen KH, Burela L, Hinnebusch AG and Valásek L (2008) elF3a cooperates with sequences $5^{\prime}$ of $\mathrm{UORF} 1$ to promote resumption of scanning by post-termination ribosomes for reinitiation on GCN4 mRNA. Genes Dev. 22(17), 2414-2425.

18. Tsuboi $T$, Takeo $S$, Iriko $H$, Jin $L$ and Tsuchimochi $M$ (2008) Wheat Germ Cell-Free System-Based Production of Malaria Proteins for Discovery of Novel Vaccine Candidates. Infection \& Immunity (Am. Soc. Microbiol.). 76(4), 1702-1708.

19. Viranov DA, Newman CL, Tyler EM, Markley JL and Shahan MN (2008) Wheat germ cell-free expression system for protein production. Curr. Protoc. Protein Sci.

20. Volyanik EV, Dalley A, Mckay IA, Leigh I, Williams NS (1993) Synthesis of preparative amounts of biologically active Interleukin-6 using a continuousflow cell-free translation system. Anal. Biochem. 214 (1), 289-294. 